Authors have nothing to disclose with regard to commercial support.

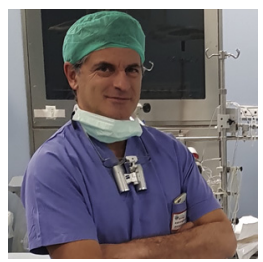

\section{ARTERIAL LACTATE LEVEL: A SIMPLE AND EFFECTIVE TOOL DURING EXTRACORPOREAL MEMBRANE OXYGENATION}

\section{To the Editor:}

Venoarterial extracorporeal membrane oxygenation (VAECMO) can provide immediate cardiopulmonary support in patients suffering from refractory cardiogenic shock (RCS). VA-ECMO support may be considered in different critical clinical scenarios leading to RCS, such as out- and inhospital cardiac arrest, ${ }^{1}$ postcardiotomy syndrome, ${ }^{2}$ outhospital hemodynamic stabilization, ${ }^{3,4}$ and mechanical complications after acute myocardial infarction. ${ }^{5,6}$ Despite the advances in the VA-ECMO technologies, early mortality in adult patients supported by VA-ECMO for RCS increased up to $82 \%$. ${ }^{7}$ Several studies aimed to provide data about predictive pre-VA-ECMO factors that might affect the early survival in these critical patients.

As part of this issue, we read with great interest the article by Fux and colleagues, ${ }^{8}$ who retrospectively evaluated preimplant variables of 105 consecutive patients supported by VA-ECMO for refractory postcardiotomy cardiogenic shock. By multivariable logistic regression, the authors reported that ischemic heart disease (IHD) (odds ratio, 7.87; 95\% confidence interval, 2.55-24.3; $P<.0001)$ and blood arterial lactate (BAL) (odds ratio, $1.22 ; 95 \%$ confidence interval, 1.07-1.40; $P=.004$ ) were independent predictors of 90-day mortality. In addition, patients with a BAL $\geq 10 \mathrm{mmol} / \mathrm{L}$ before VA-ECMO initiation had a significantly lower survival at 90 days compared with patients with a value $<10 \mathrm{mmol} / \mathrm{L}(13 \%$ vs $55 \%$, respectively; $P<.001)$. We have previously analyzed the BAL timecourse in 42 patients supported by VA-ECMO, ${ }^{9}$ and we could demonstrate that when the levels of BAL remained $\geq 3 \mathrm{mmol} / \mathrm{L}$ at 48 hours from the VA-ECMO support

\footnotetext{
The Editor welcomes submissions for possible publication in the Letters to the Editor section that consist of commentary on an article published in the Journal or other relevant issues. Authors should: • Include no more than 500 words of text, three authors, and five references. • Type with double-spacing. • See http://jtcs.ctsnetjournals.org/ misc/ifora.shtml for detailed submission instructions. • Submit the letter electronically via jtcvs.editorialmanager.com. Letters commenting on an article published in the JTCVS will be considered if they are received within 6 weeks of the time the article was published. Authors of the article being commented on will be given an opportunity of offer a timely response ( 2 weeks) to the letter. Authors of letters will be notified that the letter has been received. Unpublished letters cannot be returned.
}

initiation, the predicted probability of 30-day mortality was $52 \%$.

The study by Fux and colleagues does not provide the time-course of BAL levels during the hours following the start of VA-ECMO. Therefore, the reader cannot speculate whether BAL variations during the ECMO course may affect the weaning process and the early-term survival. Hyperlactatemia is a valid biomarker indicating a very poor tissue perfusion. Tissue perfusion can be due to (1) central factors such as inappropriate ECMO blood flow or (2) peripheral conditions such as splanchnic and peripheral vasoconstriction or severe peripheral arterial disease and finally (3) local obstruction leading to severe leg ischemia. The latter can occur up to $35 \%{ }^{10}$ of those patients receiving arterial peripheral cannulation.

In this study, ${ }^{8}$ patients with IHD have obviously a lower 90-day survival than patients without IHD, and this risk factor does not change during the VA-ECMO support. Unlike IHD, arterial lactate may change during the VA-ECMO, and its course may be extremely variable because it is affected by several factors. Therefore, it should be very important to analyze and correlate the BAL changes with the presence of the IHD. We fully agree with the authors that VA-ECMO indication for refractory postcardiotomy cardiogenic shock should be considered before the hyperlactatemia reaches very high values (ie, $>10 \mathrm{mmol} / \mathrm{L}$ ) because the prognosis in patients with IHD is undoubtedly poor. However, because the BAL is readily available in everyday practice, the narrow monitoring and the trend variations of BAL during the VA-ECMO support, both represent valid tools to facilitate the prediction of early outcome and to improve the prognosis in these critical patients.

Francesco Formica, $M D^{a}$ Stefano D'Alessandro, MD, FECTS Fabio Sangalli, $M D^{c}$

${ }^{a}$ Mechanical Circulatory Support Program Coordinator Cardiac Surgery Unit

San Gerardo Hospital Department of Medicine and Surgery University of Milano-Bicocca Monza, Italy

${ }^{b}$ Surgery Unit

Cardio-thoracic-vascular Department

San Gerardo Hospital Monza, Italy

${ }^{c}$ Department of Anesthesia and Intensive Care Medicine San Gerardo Hospital Monza, Italy

\section{References}

1. Avalli L, Maggioni E, Formica F, Redaelli G, Migliari M, Scanziani M, et al. Favourable survival of in-hospital compared to out-of-hospital refractory cardiac arrest patients treated with extracorporeal membrane oxygenation: an Italian tertiary care centre experience. Resuscitation. 2012;83:579-83. 
2. Rastan AJ, Dege A, Mohr M, Doll N, Falk V, Walther T, et al. Early and late outcomes of 517 consecutive adult patients treated with extracorporeal membrane oxygenation for refractory postcardiotomy cardiogenic shock. J Thorac Cardiovasc Surg. 2010;139:302-11.

3. Beurtheret S, Mordant P, Paoletti X, Marijon E, Celermajer DS, Léger P, et al. Emergency circulatory support in refractory cardiogenic shock patients in remote institutions: a pilot study (the cardiac-RESCUE program). Eur Heart J. 2013;34: 112-20.

4. Formica F, Avalli L, Redaelli G, Paolini G. Interhospital stabilization of adult patients with refractory cardiogenic shock by veno-arterial extracorporeal membrane oxygenation. Int J Cardiol. 2011;147:164-5.

5. Formica F, Mariani S, Singh G, D’Alessandro S, Messina LA, Jones N, et al. Postinfarction left ventricular free wall rupture: a 17-year single-centre experience. Eur J Cardiothorac Surg. 2018;53:150-6.

6. Formica F, Corti F, Avalli L, Paolini G. ECMO support for the treatment of cardiogenic shock due to left ventricular free wall rupture. Interact Cardiovasc Thorac Surg. 2005;4:30-2.

7. Squiers JJ, Lima B, DiMaio JM. Contemporary extracorporeal membrane oxygenation therapy in adults: fundamental principles and systematic review of the evidence. J Thorac Cardiovasc Surg. 2016;152:20-32.

8. Fux T, Holm M, Corbascio M, Lund LH, van der Linden J. Venoarterial extracorporeal membrane oxygenation for postcardiotomy shock: risk factors for mortality. J Thorac Cardiovasc Surg. 2018;156:1894902.

9. Formica F, Avalli L, Colagrande L, Ferro O, Greco G, Maggioni E, et al. Extracorporeal membrane oxygenation to support adult patients with cardiac failure: predictive factors of 30-day mortality. Interact Cardiovasc Thorac Surg. 2010; 10:721-6.

10. Avalli L, Sangalli F, Migliari M, Maggioni E, Gallieri S, Segramora V, et al. Early vascular complications after percutaneous cannulation for extracorporeal membrane oxygenation for cardiac assist. Minerva Anestesiol. 2016; $82: 36-43$.

https://doi.org/10.1016/j.jtcvs.2018.11.120

\section{ARTERIAL LACTATE BEFORE INITIATION OF VENOARTERIAL EXTRACORPOREAL MEMBRANE OXYGENATION FOR POSTCARDIOTOMY \\ SHOCK IMPROVES POSTIMPLANT OUTCOME PREDICTION \\ Reply to the Editor:}

The remark of Formica and colleagues in their letter that the level of arterial lactate after the start of venoarterial extracorporeal membrane oxygenation (VAECMO) may also affect short-term survival in patients with refractory postcardiotomy cardiogenic shock (RPCS) contributes to the discussion of the importance of arterial lactate as an overall predictive outcome marker in RPCS. Formica and colleagues refer to their own group's study ${ }^{1}$ of 42 surgical patients who received VA-ECMO for cardiogenic shock. Despite the relatively small number of patients, Formica and colleagues identified the arterial lactate level at 48 hours after VAECMO start as the most significant independent risk factor associated with mortality during VA-ECMO (odds ratio, 2.16; 95\% confidence interval, 1.13-4.14; $P=.019)$. Furthermore, the chosen lactate cut off level
Authors have nothing to disclose with regard to commercial support.

of $3 \mathrm{mmol} / \mathrm{L}(27.0 \mathrm{mg} / \mathrm{dL})$ or greater at 48 hours after VA-ECMO initiation was identified as predictive for 30-day mortality, with a significant difference between survivors and nonsurvivors $(54.8 \%$ vs $14.3 \%$; $P=.001)$. These interesting findings on arterial lactate behavior during VA-ECMO support, from which definite recommendations were not possible because of the limited sample size, were later supported by larger studies specifically focusing on blood lactate levels after VA-ECMO initiation. ${ }^{2-4}$

In contrast, the aim of our study of 105 patients with RPCS supported with VA-ECMO was specifically to identify factors present before VA-ECMO for postimplantation outcome prediction. ${ }^{5}$ Lactate levels during the days after VA-ECMO start are among several factors that obviously are not available to consider before VAECMO is initiated and thus not of any value for postimplantation outcome prediction before VA-ECMO initiation.

Moreover, Formica and colleagues highlight the importance of further analysis of the relationship between presence of ischemic heart disease (IHD) and changes in arterial lactate levels. Considering our focus on factors before VA-ECMO, we have performed an additional subgroup analysis of the 105 patients included in our study comparing the Kaplan-Meier survival curves with an arterial lactate cutoff level of $10 \mathrm{mmol} /$ $\mathrm{L}(90.1 \mathrm{mg} / \mathrm{dL})$ or greater in patients with or without IHD (the cutoff level of $10 \mathrm{mmol} / \mathrm{L}$ or greater was chosen because it corresponds to a specificity of $91 \%$, implying that a lactate level of $10 \mathrm{mmol} / \mathrm{L}$ identified more than $90 \%$ of the patients who died in our study population). The curves illustrate that when separating the cohort between patients with and without IHD, an arterial lactate of $10 \mathrm{mmol} / \mathrm{L}$ or greater had a significant negative impact on survival compared with an arterial lactate less than $10 \mathrm{mmol} / \mathrm{L}$, both in patients with IHD and in those without IHD, as depicted in Figure 1. Furthermore, the lowest 90-day survival (5\%) was seen in patients with a combination of IHD and arterial lactate of $10 \mathrm{mmol} / \mathrm{L}$ or greater (Figure 1, $A$ ). Conversely, patients with absence of IHD and arterial lactate less than $10 \mathrm{mmol} / \mathrm{L}$ had a much higher 90-day survival, $80 \%$ (Figure 1, B).

In conclusion, our additional analysis demonstrated that presence of IHD in these critically ill patients had a severe negative impact on 90-day survival compared 